\title{
HUBUNGAN PENGGUNAAN GADGET DENGAN KUANTITAS DAN KUALITAS TIDUR PADA ANAK SEKOLAH (KELAS IV DAN V) DI SD NEGERI 182 KOTA PEKANBARU
}

\author{
Shahibatul Hablaini ${ }^{1}$, Raja Fitrina Lestari ${ }^{2}$, Sekani Niriyah ${ }^{3}$ \\ 1,2,3 Program Studi Keperawatan STIKes Hang Tuah Pekanbaru \\ Email: Shahibatulhablaini13@gmail.com
}

\begin{abstract}
ABSTRAK
Penggunaan gadget meningkat seiring banyaknya fungsi khusus yang disediakan, salah satunya adalah akses fitur sosial media, game dan sebagainya. Kurangnya kemampuan individu mengontrol waktu penggunaan gadget mengakibatkan buruknya kuantitas dan kualitas tidur. Penelitian ini bertujuan mengetahui hubungan penggunaan gadget dengan kuantitas dan kualitas tidur pada anak sekolah (kelas IV dan V). Penelitian ini merupakan penelitian kuantitatif deskriptif korelasi dengan pendekatan cross sectional. Penelitian ini dilakukan pada tanggal 17 Mei dan 17 Juni 2019 di SD Negeri 182 Kota Pekanbaru. Populasi dalam penelitian ini adalah seluruh siswa dan siswi kelas IV dan V, dengan jumlah sampel 150 orang yang diambil secara strata dan acak, alat pengumpulan data adalah kuesioner dengan pengolahan data menggunakan komputerisasi dan analisa dilakukan secara univariat dan bivariat. Hasil menunjukkan bahwa tidak terdapat hubungan penggunaan gadget dengan kuantitas tidur pada anak sekolah (kelas IV dan V) $\left(\mathrm{P}_{\text {value }}=0,410>0,05\right)$, dan terdapat hubungan penggunaan gadget dengan kualitas tidur pada anak sekolah (kelas IV dan V) $\left(\mathrm{P}_{\text {value }}=0,041<0,05\right)$. Diharapkan kepada pihak sekolah memberikan peraturan agar anak tidak mengunakan gadget pada saat jam sekolah, serta pihak sekolah harus bekerja sama dengan orang tua dalam penggunaan gadget pada anak, agar anak terhindar penggunaan gadget yang buruk dan meningkatkan kuantitas dan kualitas tidur anak agar anak tidak mengantuk dan lebih konsentrasi di jam sekolah.
\end{abstract}

Kata Kunci : Penggunaan gadget, kuantitas dan kualitas tidur

\section{ABSTRACT}

The use of gadget increases with the number of special funtions provided, one of them is access to social media features, game and others. Lack of individual ability to control the use of gadget results in poor quantity and quality sleep. The study aims to know relations use of gadget with quantity and quality of sleep in school children (grades $I V$ and $V$ ). The research is quantitative descriptive correlation study with cross sectional approach. This research was conducted on May 17 and June 172019 in Elementary School 182 Pekanbaru. The population in this study were all students in grade $I V$ and $V$, with a sample of 150 people taken strata and random, data collection tool is a questionnaire by processing data using a computer and analysis is done in univariate and bivariate. The result showed there is no a use of gadget with quantity of sleep in children (grades $I V$ and $V$ ) (Pvalue $=0,410>0,05$ ), and the result showed there is a use of gadget with quality of sleep in school children (grades IV and V) (Pvalue =0,041 $<0,05)$. Its expected that the school provides a regulation so that children don't use gadget during school hours, as well as the school must work with parents in the use of gadget in children, so that children avoid the use of bad gadget and increase the quantity and quality of children's sleep so that children are'nt drowsy and more concentrated in school hours.

Keyword $\quad$ : Use of gadget, sleep quantity and quality

\section{PENDAHULUAN}

Perkembangan ilmu pengetahuan dan teknologi semakin canggih, ditandai dengan kemajuan teknologi dan perkembangan komunikasi. Salah satu wujud perkembangan komunikasi yang mengalami kemajuan yang sangat cepat adalah gadget. Gadget merupakan sebuah istilah berasal dari bahasa Inggris yang berarti perangkat 
Jurnal Keperawatan Abdurrab

Vol 4. No.1, Juli 2020
P-ISSN : 2541-2620

E-ISSN : 2579-8723 elektronik kecil yang memiliki fungsi khusus yang digunakan untuk alat komunikasi, mencari informasi atau browsing, sosial media, youtube, bermain game dan lainnya. Indonesia merupakan Negara yang berdampak kemajuan teknologi perkembangan yang ditandai dengan pemakai gadget terbesar di Dunia (Ameliola \& Nugraha, 2013 ; Manumpil, Ismanto \& Onibala, 2015).

Gadget pada era globalisasi sangat mudah dijumpai, karena hampir semua kalangan usia memiliki gadget. Dimulai dari anakanak sampai lansia sudah menggunakan gadget. Berdasarkan hasil survei yang dilakukan oleh Asosiasi Penyelenggara Jasa Internet Indonesia (APJII) pada tahun 2016 didapatkan pengguna gadget berdasarkan klasifikasi usia, yaitu usia 10-24 tahun $75,5 \%$ pengguna, $25-34$ tahun $75,8 \%$ pengguna, 35-44 tahun 54,7\% pengguna, 45 54 tahun $17,2 \%$ pengguna, dan $>55$ tahun $2 \%$ pengguna. Gadget sudah tuntunan untuk dimiliki seseorang dan gadget cenderung dimiliki oleh orang yang berpenghasilan tinggi dan sulit dimiliki pada orang yang berpenghasilan rendah, selain itu anak-anak sekarang menjadi target penggunaan gadget tersebut (APJII, 2016 ; Novitasari \& Khotimah, 2016).

Menurut survei lembaga Nielsen on Device Meter 2013, penduduk Indonesia menggunakan gadget selama 189 menit perhari atau lebih dari 3 jam. Berdasarkan lamanya waktu penggunaan gadget perhari, Indonesia menempati posisi pertama untuk penggunaan gadget terlama di Dunia (Pandji, 2014).

Penggunaan gadget pada anak juga mempunyai dampak positif dan negatif. Dampak positif dari penggunaan gadget antara lain untuk memudahkan seorang anak dalam mengasah kreativitas dan kecerdasan anak. Dampak negatif dari penggunaan gadget terbagi dua yaitu terhadap psikologis dan kesehatan. Dampak psikologis tersebut adalah anak-anak menjadi pribadi tertutup, suka menyendiri, ancaman cyberbullying dan menikmati dunia yang ada di dalam gadget tersebut sehingga melupakan kesenangan bermain dengan teman-teman seumuran mereka maupun dengan anggotaanggota keluarganya, sedangkan dampak terhadap kesehatan yaitu kesehatan otak terganggu, kesehatan mata terganggu, kesehatan tangan terganggu, terpapar radiasi, dan gangguan tidur. Hal itu tentunya akan berdampak buruk terhadap perkembangan tumbuh anak dan kesehatan anak, salah satu masalah kesehatan anak tersebut adalah kurangnya kebutuhan tidur (Iswidharmanjaya \& Agency, 2014).

Kualitas tidur merupakan kepuasan seseorang terhadap tidur, kualitas tidur yang baik akan menghasilkan kesegaran dan kebugaran pada saat terbangun. Tidur yang tidak berkualitas baik dapat menyebabkan gangguan keseimbangan fisiologis dan psikologis (Mubarak, Indrawati \& Susanto, 2015).

Kebutuhan tidur dapat terganggu dari berbagai kebiasaan dan perilaku gangguan tidur, seperti sering menonton televisi saat mau tidur, serta penggunaan gadget pada anak sebelum tidur. Interaksi sosial dan karakteristik temperamen individu memegang peran penting dalam kualitas tidur, pada anak yang mana anak sekolah membutuhkan tidur selama 10 jam/hari (Mubarak, Indrawati \& Susanto, 2015).

Berdasarkan hasil survei awal yang dilakukan oleh penulis pada tanggal 26 Maret 2019 di SD Negeri 182 Kota Pekanbaru didapatkan 245 anak sekolah (kelas IV dan V). Melalui wawancara pada anak kelas VA yaitu 36 anak, didapatkan 23 anak menggunakan gadget dengan milik pribadi. 9 anak mengaku dibelikan gadget sejak 2 tahun yang lalu dan 14 anak mengatakan sudah 1 tahun 6 bulan dibelikan 
gadget. Penggunaan gadget bukan hanya dirumah, namun kadang-kadang dibawa ke sekolah untuk digunakan saat istirahat dan pada saat kegiatan ekstrakurikuler. Anak juga menggunakan gadget sebelum tidur sampai pukul 22.00 dan kadang juga sampai pukul 24.00 malam untuk bermain game, membuka sosial media, menonton video, melihat gambar hingga chatting, sehingga anak sulit untuk dibangunkan pagi hari, hasil wawancara dengan guru wali kelas didapatkan data 5 anak tidak konsentrasi saat di kelas jam pembelajaran sekolah dan selebihnya anak sering mengantuk di kelas.

Sedangkan 13 anak menggunakan gadget dengan punya Ibu anak tersebut, saat di wawancarai bahwa anak menggunakan gadget saat sepulang sekolah dan anak itu juga menggunakan gadget secara terbatas karena punya Ibu tapi anak itu memainkan gadget hingga malam sampai pukul 22.00 malam dan memainkan game, membuka sosial media, menonton video, melihat gambar serta chatting, sehingga anak sulit dibangunkan pagi hari. Dimana pada era globalisasi saat ini telah menjadikan gadget sebagai salah satu alat komunikasi sehingga seseorang sering menggunakannya. Bahkan, sudah menjadi kebiasaan dan kecanduaan serta menggangu kuantitas dan kualitas tidur pada setiap individu, hal ini tidak hanya terjadi pada dewasa, tetapi juga terjadi pada anak.

\section{METODELOGI PENELITIAN}

Jenis penelitian ini adalah kuantitatif deskriptif korelasi dengan pendekatan cross sectional. Populasi yang dimaksud dalam penelitian ini adalah anak SD Negeri 182 Kota Pekanbaru (kelas IV dan V) yang berjumlah 245 orang. Sampel pada penelitian ini adalah anak kelas IV dan $\mathrm{V}$ yang memenuhi kriteria dengan jumlah sampel 150 orang. Pengambilan sampel pada penelitian ini menggunakan teknik random sampling, penelitian ini dilakukan secara strata dan dapat diambil sampel secara acak, dengan alat pengumpulan data menggunakan lembar kuesioner.

\section{HASIL PENELITIAN}

Hasil penelitian yang dilakukan dari bulan Mei sampai bulan Juni 2019 pada 150 responden anak kelas IV dan $\mathrm{V}$ di SD Negeri 182 Kota Pekanbaru, dengan data yang diperoleh sebagai berikut.

\section{A. Analisis Univariat}

\section{Karakteristik Responden}

a. Umur

Tabel 1. Distribusi Frekuensi Berdasarkan

Umur Responden di SD Negeri 182 Kota Pekanbaru Tahun 2019

\begin{tabular}{llcc}
\hline No. & Variabel & $\begin{array}{c}\text { Frekuensi } \\
(\mathrm{n})\end{array}$ & $\begin{array}{c}\text { Persentase } \\
(\%)\end{array}$ \\
\hline 1. & Umur & & \\
& $\begin{array}{l}\text { a. Masa } \\
\text { kanak- }\end{array}$ & 67 & 44,7 \\
& kanak (5- & & \\
& 11 tahun) & & \\
& b. Masa \\
& remaja \\
awal (12- & 83 & 55,3 \\
& & \\
\hline Totahun $)$ & & \\
\hline & 150 & 100 \\
\hline
\end{tabular}

Berdasarkan tabel 1 diatas dapat dilihat dari 150 responden pada penelitian ini didapatkan sebagian besar responden dalam kelompok umur masa remaja awal (12-16 tahun) yaitu $83(55,3 \%)$ responden.

b. Jenis Kelamin

Tabel 2. Distribusi Frekuensi Berdasarkan Jenis Kelamin Responden di SD Negeri 182 Kota Pekanbaru Tahun 2019

\begin{tabular}{llcc}
\hline No. & Variabel & $\begin{array}{c}\text { Frekuensi } \\
(\mathrm{n})\end{array}$ & $\begin{array}{c}\text { Persentase } \\
(\%)\end{array}$ \\
\hline 1. & Jenis Kelamin & & \\
& a. Laki-laki & 70 & 46,7 \\
& b. Perempuan & 80 & 53,3 \\
\hline & $\quad$ Total & 150 & 100 \\
\hline
\end{tabular}


Berdasarkan tabel 2 diatas dapat dilihat dari 150 responden pada penelitian ini didapatkan sebagian besar responden berjenis kelamin perempuan yaitu 80 $(53,3 \%)$ responden.

\section{c. Fungsi Penggunaan Gadget}

Tabel 3. Distribusi Frekuensi Fungsi

Penggunaan Gadget di SD Negeri 182 Kota Pekanbaru Tahun 2019

\begin{tabular}{llcc}
\hline No. & Variabel & $\begin{array}{c}\text { Frekuensi } \\
(\mathrm{n})\end{array}$ & $\begin{array}{c}\text { Persentase } \\
(\%)\end{array}$ \\
\hline 1. & Fungsi & & \\
& Penggunaan & & \\
& Gadget & & \\
a. Youtube & 21 & 14,0 \\
b. Game & 98 & 65,3 \\
c. Sosial & 16 & 10,7 \\
& Media & & \\
d. Komunikasi & 15 & 10,0 \\
\hline & Total & 150 & 100 \\
\hline
\end{tabular}

Berdasarkan tabel 3 diatas diketahui bahwa distribusi frekuensi fungsi penggunaan gadget dari 150 responden pada penelitian ini didapatkan sebagian besar responden memiliki fungsi penggunaan gadget untuk game $98(65,3 \%)$ responden.

d. Komponen Kualitas Tidur

Tabel 4. Distribusi Frekuensi Komponen

Kualitas Tidur di SD Negeri 182 Kota

Pekanbaru Tahun 2019

\begin{tabular}{|c|c|c|c|}
\hline No. & Variabel & $\begin{array}{l}\text { Frekuensi } \\
\text { (n) }\end{array}$ & $\begin{array}{c}\text { Persentase } \\
(\%)\end{array}$ \\
\hline \multirow[t]{7}{*}{1.} & Subjektif & & \\
\hline & kualitas tidur & & \\
\hline & a. Sangat baik & 28 & 18,7 \\
\hline & b. Cukup baik & 92 & 61,3 \\
\hline & c. Cukup buruk & 29 & 19,3 \\
\hline & $\begin{array}{l}\text { d. Sangat } \\
\text { buruk }\end{array}$ & 1 & 0,7 \\
\hline & Total & 150 & 100 \\
\hline \multirow[t]{4}{*}{2.} & Latensi tidur & & \\
\hline & $\begin{array}{l}\text { a. Latensi tidur } \\
0\end{array}$ & 40 & 26,7 \\
\hline & $\begin{array}{l}\text { b. Latensi tidur } \\
1-2\end{array}$ & 51 & 34,0 \\
\hline & c. Latensi tidur & 57 & 38,0 \\
\hline
\end{tabular}

$$
\text { 3-4 }
$$

d. Latensi tidur $2 \quad 1,3$

\begin{tabular}{|c|c|c|c|}
\hline & Total & 150 & 100 \\
\hline \multirow[t]{6}{*}{3.} & Durasi tidur & & \\
\hline & $\begin{array}{l}\text { a. Durasi tidur } \\
>10 \mathrm{jam}\end{array}$ & 30 & 20,0 \\
\hline & $\begin{array}{l}\text { b. Durasi tidur } \\
9-10 \text { jam }\end{array}$ & 29 & 19,3 \\
\hline & $\begin{array}{l}\text { c. Durasi tidur } \\
8-9 \text { jam }\end{array}$ & 33 & 22,0 \\
\hline & $\begin{array}{l}\text { d. Durasi tidur } \\
<7 \text { jam }\end{array}$ & 58 & 38,7 \\
\hline & Total & 150 & 100 \\
\hline \multirow[t]{8}{*}{4.} & Efisiensi tidur & & \\
\hline & $\begin{array}{l}\text { a. Efisiensi } \\
\text { tidur }>85 \%\end{array}$ & 8 & 5,3 \\
\hline & b. Efisiensi & 4 & 2,7 \\
\hline & $\begin{array}{l}\text { tidur } \\
85 \%\end{array}$ & & \\
\hline & c. Efisiensi & 14 & 9,3 \\
\hline & $\begin{array}{l}\text { tidur } 65- \\
74 \%\end{array}$ & & \\
\hline & $\begin{array}{ll}\text { d. } & \text { Efisiensi } \\
\text { tidur }<65 \%\end{array}$ & 124 & 82,7 \\
\hline & Total & 150 & 100 \\
\hline
\end{tabular}

5. Gangguan tidur

a. Gangguan $\quad 81 \quad 54,0$
tidur $1-9$

b. Gangguan $\quad 67 \quad 44,7$ tidur 10-18

c. Gangguan $2 \quad 1,3$ tidur 19-27

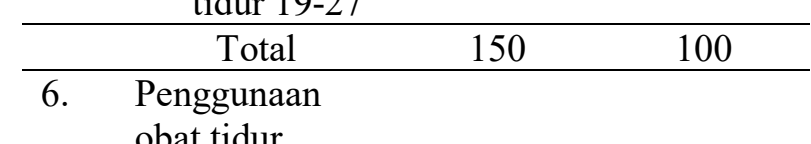

obat tidur

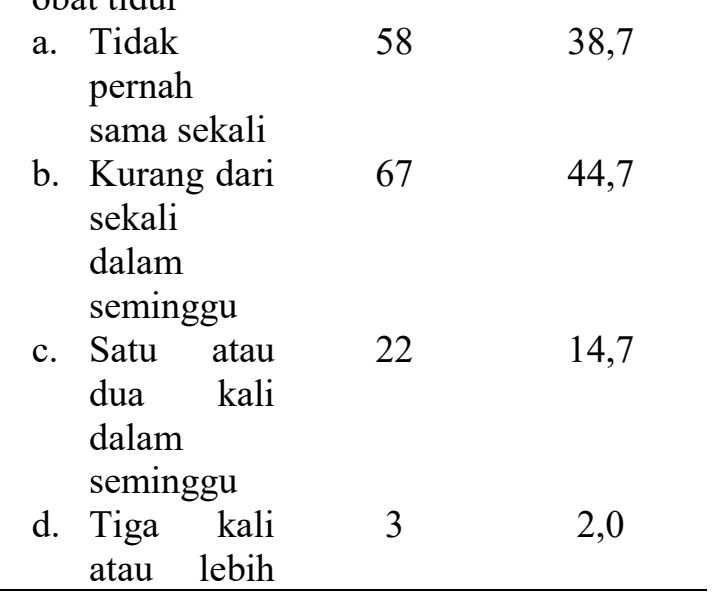




\begin{tabular}{|c|c|c|c|}
\hline & Total & 150 & 100 \\
\hline \multirow[t]{6}{*}{7.} & $\begin{array}{l}\text { Gangguan } \\
\text { aktifitas sehari- } \\
\text { hari }\end{array}$ & & \\
\hline & $\begin{array}{l}\text { a. Disfungsi } \\
\text { aktivitas } \\
\text { siang hari } 0\end{array}$ & 24 & 16,0 \\
\hline & $\begin{array}{l}\text { b. Disfungsi } \\
\text { aktivitas } \\
\text { siang hari } \\
1-2\end{array}$ & 77 & 51,3 \\
\hline & $\begin{array}{l}\text { c. Disfungsi } \\
\text { aktivitas } \\
\text { siang hari } \\
3-4\end{array}$ & 45 & 30,0 \\
\hline & $\begin{array}{l}\text { d. Disfungsi } \\
\text { aktivitas } \\
\text { siang hari } \\
\text { 5-6 }\end{array}$ & 4 & 2,7 \\
\hline & Total & 150 & 100 \\
\hline
\end{tabular}

Berdasarkan tabel 4 diatas diketahui bahwa distribusi frekuensi komponen kualitas tidur dari 150 responden pada penelitian ini didapatkan sebagian besar responden subjektif kualitas tidur cukup baik sebanyak $92(61,3 \%)$ responden, latensi tidur 3-4 sebanyak $57(38,0 \%)$ responden, durasi tidur $<7$ jam sebanyak $58(38,7 \%)$ responden, efisiensi tidur $<65 \%$ sebanyak $124(82,7 \%)$ responden, gangguan tidur 1-9 sebanyak 81 $(54,0 \%)$ responden, penggunaan obat tidur kurang dari sekali dalam seminggu 67 (44,7\%) responden, dan gangguan aktifitas sehari-hari 1-2 sebanyak $77 \quad(51,3 \%)$ responden.

\section{Variabel Independen}

a. Penggunaan Gadget

Tabel 5. Distribusi Frekuensi

Berdasarkan Variabel Penggunaan Gadget pada Anak Sekolah (Kelas IV dan V) di SD

Negeri 182 Kota Pekanbaru Tahun 2019

\begin{tabular}{cccc}
\hline No. & $\begin{array}{c}\text { Penggunaan } \\
\text { Gadget }\end{array}$ & $\begin{array}{c}\text { Frekuensi } \\
(\mathrm{n})\end{array}$ & $\begin{array}{c}\text { Persentase } \\
(\%)\end{array}$ \\
\hline 1. & $\begin{array}{l}\text { Baik jika }<1 \\
\text { jam perhari }\end{array}$ & 65 & 43,3 \\
& &
\end{tabular}

2. $\quad$ Buruk jika $\geq \quad 85 \quad 56,7$

\begin{tabular}{l} 
1 jam perhari \\
Total 150 \\
\hline Berdasarkan tabel 5 dapat dilihat dari 150 \\
responden pada penelitian ini didapatkan \\
sebagian besar responden menggunakan \\
waktu penggunaan gadget yang buruk \\
sebanyak $85(56,7 \%)$ responden.
\end{tabular}

\section{Variabel Dependen}

a. Kuantitas Tidur

Tabel 6. Distribusi Frekuensi

Berdasarkan Variabel Kuantitas Tidur pada

Anak Sekolah (Kelas IV dan V) di SD

Negeri 182 Kota Pekanbaru Tahun 2019

\begin{tabular}{clcc}
\hline No. & $\begin{array}{l}\text { Kuantitas } \\
\text { Tidur }\end{array}$ & $\begin{array}{c}\text { Frekuensi } \\
(\mathrm{n})\end{array}$ & $\begin{array}{c}\text { Persentase } \\
(\%)\end{array}$ \\
\hline 1. & $\begin{array}{l}\text { Buruk jika } \\
<10 \text { jam }\end{array}$ & 120 & 80,0 \\
& $\begin{array}{l}\text { perhari } \\
\text { Baik jika } \geq \\
10 \quad \text { jam } \\
\text { perhari }\end{array}$ & 30 & 20,0 \\
\multicolumn{2}{c}{ Total } & 150 & 100 \\
\hline
\end{tabular}

Berdasarkan tabel 6 dapat dilihat dari 150 responden pada penelitian ini didapatkan sebagian besar responden memiliki kuantitas tidur yang buruk sebanyak $120 \quad(80,0 \%)$ responden.

\section{b. Kualitas Tidur}

Tabel 7. Distribusi Frekuensi

Berdasarkan Variabel Kualitas Tidur pada Anak Sekolah (Kelas IV dan V) di SD

Negeri 182 Kota Pekanbaru Tahun 2019

\begin{tabular}{clcc}
\hline No. & $\begin{array}{l}\text { Kualitas } \\
\text { Tidur }\end{array}$ & $\begin{array}{c}\text { Frekuensi } \\
\text { (n) }\end{array}$ & $\begin{array}{c}\text { Persentase } \\
(\%)\end{array}$ \\
\hline 1. & $\begin{array}{l}\text { Baik jika } \\
\text { kualitas } \\
\text { tidur } \leq 5\end{array}$ & 11 & 7,3 \\
2. & $\begin{array}{l}\text { Buruk jika } \\
\text { kualitas } \\
\text { tidur }>5\end{array}$ & 139 & 92,7 \\
\hline & Total & 150 & 100 \\
\hline
\end{tabular}


Jurnal Keperawatan Abdurrab

Vol 4. No.1, Juli 2020

Berdasarkan tabel 7 dapat dilihat dari 150 responden pada penelitian ini didapatkan sebagian besar responden memiliki kualitas tidur yang buruk sebanyak 139 (92,7\%) responden.

\section{B. Analisis Bivariat}

1. Hubungan Penggunaan Gadget dengan Kuantitas Tidur pada Anak Sekolah (Kelas IV dan V) di SD Negeri 182 Kota Pekanbaru

Tabel 8. Hubungan Penggunaan Gadget dengan Kuantitas Tidur Anak Sekolah (Kelas IV dan V) di SD Negeri 182 Kota Pekanbaru Tahun 2019

\begin{tabular}{|c|c|c|c|c|c|c|c|c|}
\hline \multirow{3}{*}{$\begin{array}{l}\text { Penggu } \\
\text { naan } \\
\text { Gadget }\end{array}$} & \multicolumn{6}{|c|}{ Kuantitas Tidur } & \multirow{3}{*}{$\begin{array}{c}\mathrm{P} \\
\text { Val } \\
u e\end{array}$} & \multirow{3}{*}{$\begin{array}{c}\mathrm{PO} \\
\mathrm{R}\end{array}$} \\
\hline & \multicolumn{2}{|c|}{ Buruk } & \multicolumn{2}{|c|}{ Baik } & \multicolumn{2}{|c|}{ Total } & & \\
\hline & $\mathrm{N}$ & $\%$ & $\mathrm{~N}$ & $\%$ & $\mathrm{~N}$ & $\%$ & & \\
\hline \multirow[t]{2}{*}{ Buruk } & 7 & 82 & 1 & 17 & 8 & 1 & 0,4 & 0,71 \\
\hline & 0 & ,4 & 5 & ,6 & 5 & $\begin{array}{l}0 \\
0\end{array}$ & 10 & $\begin{array}{c}4 \\
(0,3\end{array}$ \\
\hline \multirow[t]{2}{*}{ Baik } & 5 & 76 & 1 & 23 & 6 & 1 & & $20-$ \\
\hline & 0 & ,9 & 5 & ,1 & 5 & $\begin{array}{l}0 \\
0\end{array}$ & & $\begin{array}{c}1,59 \\
4)\end{array}$ \\
\hline \multirow[t]{3}{*}{ Total } & 1 & 80 & 3 & 20 & 1 & 1 & & \\
\hline & 2 & ,0 & 0 &, 0 & 5 & 0 & & \\
\hline & 0 & & & & 0 & 0 & & \\
\hline
\end{tabular}

Berdasarkan tabel 8 diatas diketahui dari 85 anak yang menggunakan gadget buruk, 70 $(82,4 \%)$ anak memiliki kuantitas tidur yang buruk. Sebanyak 65 anak menggunakan gadget baik, 50 (76,9\%) anak memiliki kuantitas tidur yang buruk. Hasil uji chi square didapat $p_{\text {value }}=0,410>0,05$ hal ini berarti tidak terdapat hubungan penggunaan gadget dengan kuantitas tidur pada anak sekolah (kelas IV dan V), analisis keeratan hubungan dua variabel didapatkan nilai prevalensi odss ration $(\mathrm{POR})=0,714$ (0,320-1,594) yang artinya responden menggunakan gadget yang buruk berisiko 0,714 kali memiliki kuantitas tidur yang buruk jika dibandingkan dengan responden menggunakan gadget yang baik.
P-ISSN : 2541-2620

E-ISSN : 2579-8723

\section{Hubungan Penggunaan Gadget dengan Kualitas Tidur pada Anak Sekolah (Kelas IV dan V) di SD Negeri 182 Kota Pekanbaru}

Tabel 9. Hubungan Penggunaan Gadget dengan Kualitas Tidur pada Anak Sekolah

(Kelas IV dan V) di SD Negeri 182 Kota

Pekanbaru Tahun 2019

\begin{tabular}{lcccccccc}
\hline Pengg & \multicolumn{4}{c}{ Kualitas Tidur } & P & PO \\
\cline { 2 - 6 } unaan & \multicolumn{4}{c}{ Buruk } & \multicolumn{3}{c}{ Baik } & \multicolumn{2}{c}{ Total } & Val & $\mathrm{R}$ \\
\cline { 2 - 6 } Gadget & $\mathrm{N}$ & $\%$ & $\mathrm{~N}$ & $\%$ & $\mathrm{~N}$ & $\%$ & ue & \\
& & & & & & & & \\
\hline Buruk & 8 & 96 & 3 & 3, & 8 & 1 & 0,0 & 3,83 \\
& 2 &, 5 & & 5 & 5 & 0 & 41 & 6 \\
& & & & & & 0 & & $(0,9$ \\
Baik & 5 & 87 & 8 & 12 & 6 & 1 & & $76-$ \\
& 7 &, 7 & &, 3 & 5 & 0 & & 15,0 \\
& & & & & & 0 & & $86)$ \\
\hline Total & 1 & 92 & 1 & 7, & 1 & 1 & & \\
& 3 &, 7 & 1 & 3 & 5 & 0 & & \\
& 9 & & & & 0 & 0 & & \\
\hline
\end{tabular}

Berdasarkan tabel 9 diatas diketahui dari 85 anak yang menggunakan gadget buruk, 82 $(96,5 \%)$ anak yang memiliki kualitas tidur yang buruk. Sebanyak 65 anak yang menggunakan gadget baik, 57 (87,7\%) anak memiliki kualitas tidur buruk. Hasil uji chi square didapat $\mathrm{p}_{\text {value }}=0,041<0,05$ hal ini berarti terdapat hubungan penggunaan gadget dengan kualitas tidur pada anak sekolah (kelas IV dan V), analisis keeratan hubungan dua variabel didapatkan nilai prevalensi odss ratio $(\mathrm{POR})=3,836(0,976-$ 15,086) yang artinya responden menggunakan gadget yang buruk berisiko 3,836 kali memiliki kualitas tidur yang buruk jika dibandingkan dengan responden menggunakan gadget baik.

\section{PEMBAHASAN}

\section{A. Analisis Univariat}

\section{Penggunaan Gadget}


Jurnal Keperawatan Abdurrab

Vol 4. No.1, Juli 2020

Berdasarkan distribusi frekuensi dari penggunaan gadget didapatkan dari 150 responden pada penelitian ini sebagian besar responden memiliki penggunaan gadget yang buruk sebanyak $85(56,7 \%)$ responden. Menurut Prasetyaningsih (2017) dalam segi waktu anak menggunakan gadget pada saat pulang sekolah dan setelah belajar pada malam hari yaitu dalam waktu kurang lebih 3 sampai 6 jam perhari. Anak menggunakan gadget untuk bermain game online atau game offline, untuk browsing mencari informasi atau tugas dan tidak berkemungkinan bahwa anak menggunakan gadget untuk sosial media.

Penelitian ini juga didukung oleh Syamsoedin (2015) tentang hubungan durasi penggunaan media sosial dengan kejadian insomnia yang menjelaskan bahwa durasi penggunaan gadget yaitu pada jangka waktu 3 sampai 4 jam sehari pada siswa sekolah yang berjumlah 31 siswa $(50,0 \%)$. Hal ini sejalan dengan penelitian Rozalia (2017) intensitas penggunaan gadget yaitu seberapa sering anak menggunakan atau memanfaatkan gadget.

Menurut Saifullah (2017) bahwa sebagian besar responden menggunakan gadget selama lebih dari 12 jam dalam sehari, hal ini memicu terjadinya kecanduan dalam penggunaan gadget. Tujuan menggunakan gadget untuk mengikuti tren dan gaya hidup masa kini dan menunjukkan karakteristik kecanduan gadget pada responden seperti menganggap gadget yang paling penting dan tidak dapat mengontrol penggunaan gadget merupakan keadaan yang mudah terjadi pada anak sekolah, karena usia sekolah merupakan masa peralihan menuju masa remaja sehingga sangat penting dikonrol oleh orang tua.

Peneliti berasumsi bahwa penggunaan gadget buruk pada anak disebabkan karena
P-ISSN : 2541-2620

E-ISSN : 2579-8723

intensitas waktu penggunaan gadget yang berlebihan yaitu lebih dari 1 jam dan anak menggunakan gadget untuk berbagai fungsi seperti untuk browsing, bermain game bahkan untuk sosial media pada gadget. Kecanduan penggunaan gadget pada anak sekolah sangat mudah terjadi, karena rasa ingin tahunya sangat tinggi dan anak sekolah adalah masa peralihan menuju remaja sehingga anak perlu di kontrol setiap aktivitas anak oleh orang tua.

\section{Kuantitas Tidur}

Berdasarkan distribusi frekuensi dari kuantitas tidur pada anak sekolah didapatkan dari 150 responden pada penelitian ini sebagian besar responden memiliki kuantitas tidur pada anak sekolah yang buruk sebanyak $120(80,0 \%)$ responden. Menurut Potter \& Perry (2012) mengatakan bahwa kebutuhan tidur pada anak sekolah 9 sampai 10 jam setiap malamnya, anak usia sekolah biasanya tidak membutuhkan tidur siang, anak usia sekolah 10 sampai 13 tahun biasanya tidur hingga larut malam sehingga orang tua untuk tidur pada anak lebih menggunakan pendekatan tegas dan konsisten agar anak tidur tidak larut malam.

Menurut penelitian Hanifratiwi tentang hubungan gangguan tidur terhadap kualitas hidup anak dengan obesitas (2013) anak sekolah memiliki durasi tidur yang berbeda ketika libur sekolah, saat hari sekolah anak memiliki durasi tidur $<8$ jam perhari sedangkan durasi tidur anak ketika libur $>8$ jam perhari. Penelitian ini juga didukung oleh penelitian Ulfiana (2018) diperoleh dari mayoritas siswa tidur dalam sehari adalah 8 sampai 9 jam sehari.

Peneliti berasumsi bahwa kuantitas tidur anak sekolah yang baik adalah 10 jam pada malam harinya, sedangkan tidur yang buruk pada anak sekolah yaitu $<10$ jam pada malam harinya hal ini disebabkan oleh 
Jurnal Keperawatan Abdurrab

Vol 4. No.1, Juli 2020

berbagai aktivitas yang dilakukan sebelum tidur sehingga membuat anak tidak cukup durasi tidurnya. Sehingga kebiasaan anak sebelum tidur sangat perlu di perhatikan oleh orang tua.

\section{Kualitas Tidur}

Berdasarkan distribusi frekuensi dari kualitas tidur pada anak sekolah didapatkan dari 150 responden pada penelitian ini sebagian besar respoden memiliki kualitas tidur pada anak sekolah yang buruk sebanyak 139 (92,7\%) responden. Kualitas tidur adalah suatu keadaan tidur yang dijalani seseorang individu menghasilkan kesegaran dan kebugaran saat terbangun. Waktu tidur anak sekolah adalah 10 jam/hari, anak mempunyai kualitas tidur yang baik ditandai dengan tidur yang terlelap dan badan yang segar setelah bangun dari tidur (Poerwopoespito, 2010).

Menurut Masyeni (2010) anak memiliki kualitas tidur yang buruk ketika usia sekolah yaitu usia 10-12 tahun. Seseorang yang mempunyai kualitas tidur yang rendah atau buruk pada saat melakukan aktivitas seharihari sehingga sering merasa mengantuk. Hal ini sejalan dengan penelitian Asy (2018) kualitas tidur buruk dipengaruhi oleh aktivitas sehari-hari dimana rasa ingin tahu anak yang tinggi untuk melakukan segala sesuatu yang belum diketahui. Selain faktor sosial, faktor elektronik juga mempengaruhi kualitas tidur anak seperti televisi, computer dan gadget.

Menurut Syamsoedin (2015) pada penelitian hubungan durasi penggunaan media sosial dengan kejadian insomnia bahwa terdapat siswa tidur kurang dari 8 jam per hari. Faktor gadget dapat mempengaruhi kualitas tidur seseorang, seperti mengakses internet dengan peralatan elektronik yang ada dikamar seperti televisi, gadget, dan computer.
Peneliti berasumsi bahwa kualitas tidur yang buruk pada anak sekolah dapat disebabkan oleh berbagai faktor. Perlunya perhatian khusus untuk memenuhi kualitas tidur anak karena merupakan kondisi hal yang penting bagi kesehatan. Aktivitas sehari-hari perlu diperhatikan seperti anak perlu pembatasan penggunaan gadget sehingga dapat meningkatkan kualitas tidur yang baik pada anak. Jika kualitas tidur yang baik maka tubuh akan selalu sehat dan bugar serta bersemangat untuk beraktivitas disiang hari.

\section{B. Analisis Bivariat}

1. Hubungan Penggunaan Gadget dengan Kuantitas Tidur pada Anak Sekolah (Kelas IV dan V) di SD Negeri 182 Kota Pekanbaru

Berdasarkan hasil penelitian diketahui tidak terdapat hubungan penggunaan gadget dengan kuantitas tidur pada anak sekolah (kelas IV dan V) di SD Negeri 182 Kota Pekanbaru, dengan $p_{\text {value }}>0,05=0,410$. POR 0,714 yang artinya responden menggunakan gadget buruk berisiko 0,714 kali memiliki kuantitas tidur yang buruk jika dibandingkan dengan responden yang menggunakan gadget yang baik. Penelitian ini tidak sejalan dengan teori yang dikemukakan oleh Mawitjere (2017) dalam penelitian hubungan lama penggunaan gadget dengan kejadian insomnia bahwa penggunaan gadget yang berlebihan sering kali membuat anak mengalami waktu tidur yang tidak cukup, walaupun hanya sekedar mengakses jejaring sosial, bermain game, atau berinteraksi dengan lainnya sebelum jam tidur dapat mengganggu pola tidur yang cukup.

Syamsoedin (2015) mendukung pernyataan yang tertulis diatas bahwa penggunaan gadget sangat populer pada anak sekolah, dimana gadget tersebut merupakan alat yang memaparkan cahaya yang apabila semakin lama penggunaan gadget tersebut akan 
Jurnal Keperawatan Abdurrab

Vol 4. No.1, Juli 2020

mengganggu pengaturan dari hormon melatonin sehingga membuat kuantitas tidur yang buruk pada anak. Ketidakmampuan anak dalam manajemen waktu dalam penggunaan gadget dengan baik dan benar ketika berada di sekolah maupun di rumah, akan berdampak pada ketidakaturan pola istirahat dan tidur pada anak sehingga membuat tidak terpenuhnya pola tidur yang baik pada anak 10 jam setiap malamnya.

Peneliti berasumsi bahwa tidak terdapat hubungan penggunaan gadget dengan kuantitas tidur anak sekolah (kelas IV dan V). Hal ini dapat disebabkan oleh berbagai faktor diantaranya anak tidak menggunakan gadget sebelum tidur, anak menggunakan gadget disiang hari saat pulang sekolah, dan kebiasaan pola tidur anak.

\section{Hubungan Penggunaan Gadget Kualitas Tidur pada Anak Sekolah (Kelas IV dan V) di SD Negeri 182 Kota Pekanbaru}

Berdasarkan hasil penelitian diketahui bahwa terdapat hubungan penggunaan gadget dengan kualitas tidur pada anak sekolah (kelas IV dan V) di SD Negeri 182 Kota Pekanbaru, dengan $p_{\text {value }}<0,05=$ 0,041 . POR 3,836 yang artinya responden menggunakan gadget buruk berisiko 3,836 kali memiliki kualitas tidur buruk jika dibandingkan dengan responden yang menggunakan gadget baik.

Penelitian ini sejalan dengan teori yang dikemukakan oleh Permadi (2017) bahwa ada hubungan perilaku penggunaan gadget dengan kualitas tidur pada anak, yaitu semakin sering dalam penggunaan gadget maka semakin kurang terpenuhi kualitas tidurnya, dan semakin tidak pernah atau jarang dalam penggunaan gadget maka semakin tercukupi kualitas tidurnya. Hal ini juga serupa dengan penelitian Meirianto (2018) bahwa ada hubungan kecanduan
P-ISSN : 2541-2620

E-ISSN : 2579-8723 smarthphone dengan kualitas tidur pada anak.

Menurut penelitian Puspa, Loebis \& Nuswantoro (2018) mengatakan bahwa kebiasaan buruk saat menggunakan gadget adalah jarak pandang mata dan layar gadget yang sangat dekat, sehingga membuat mata menjadi perih karena terpapar sinar radiasi penuh dan pencahayaan gadget yang terlalu terang. Penelitian ini juga didukung oleh Nafiah (2018) bahwa ada hubungan durasi penggunaan sosial media terhadap kualitas tidur. Penggunaan gadget pada anak tanpa pengawasan dan pembatasan dari orang tua, karena terlalu lama menggunakan gadget sehingga membuat anak menjadi canduan sehingga kualitas tidur menurun. Menurut penelitian Putri (2018) bahwa terdapat hubungan kecanduan smarthphone terhadap kualitas tidur, kecanduan smarthphone memiliki pengaruh 13\% terhadap kualitas tidur dan selebihnya karena faktor lainnya.

Peneliti berasumsi bahwa terdapat hubungan penggunaan gadget dengan kualitas tidur pada anak sekolah (kelas IV dan V). Responden yang memiliki kualitas tidur yang buruk dapat disebabkan oleh faktor elektronik seperti penggunaan gadget. Penggunaan gadget yang berlebihan dan apabila semakin di biarkan anak menggunakan gadget tersebut akan berdampak buruk pada kesehatan anak, hal ini perlu pengawasan yang ketat bagi orang tua dalam memberikan anak sebuah gadget.

\section{KESIMPULAN}

Hasil analisis bivariat menunjukkan bahwa tidak terdapat hubungan penggunaan gadget dengan kuantitas tidur pada anak sekolah (kelas IV dan V) dan terdapat hubungan penggunaan gadget dengan kualitas tidur pada anak sekolah (kelas IV dan V). Hal ini menyebabkan tidak terdapat hubungan penggunaan gadget dengan kuantitas tidur 
salah satunya anak tidak menggunakan gadget sebelum tidur, anak menggunakan gadget disiang hari saat pulang sekolah dan kebiasaan pola tidur anak. Sedangkan pada penggunaan gadget dengan kualitas tidur pada anak terdapat hubungan, apabila penggunaan gadget berlebihan semakin dibiarkan akan berdampak buruk pada kesehatan anak, hal ini perlu pengawasan yang ketat bagi orang tua dalam memberikan sebuah gadget.

\section{SARAN}

1. Bagi Institusi Pendidikan

Diharapkan bagi institusi pendidikan Pekanbaru dapat menambah bahan bacaan dan ilmu pengetahuan diperpustakaan khususnya mengenai penggunaan gadget, kuantitas dan kualitas tidur pada anak sekolah.

2. Bagi Keperawatan

Diharapkan agar mahasiswa keperawatan bukan hanya fokus pada kesehatan dan pengobatan saja, tapi fokus pada pencegahan terutama pada kuantitas dan kualitas tidur.

3. Bagi Sekolah

Diharapkan bagi sekolah dapat memberikan informasi tentang masalah penggunaan gadget, kuantitas dan kualitas tidur, serta pihak sekolah juga memberikan peraturan agar anak tidak menggunakan gadget pada saat jam sekolah, dan apabila anak tetap menggunakan gadget pada saat jam sekolah maka anak diberi hukuman dengan bekerja sama dengan orang tua murid.

4. Bagi Peneliti Selanjutnya

Diharapkan bagi peneliti selanjutnya dapat melakukan penelitian menggunakan jenis penelitian kualitatif dan wawancara mendalam agar informasi yang diperoleh lebih akurat serta melakukan penelitian pada wilayah yang lebih luas.

\section{DAFTAR PUSTAKA}

Ameliola, S., \& Nugraha, H. D. (2013). Perkembangan Media Informasi Dan Teknologi Terhadap Anak Dalam Era Globalisasi.https://icssis.files.wordpres s.com/2013/09/2013-02-29.pdf :362371. Diakses pada tanggal 10 Maret 2019.

Asosiasi Penyelenggara Jasa Internet Indonesia. (2016). Penetrasi \& Perilaku Pengguna Internet Indonesia. Journal Survey 2016.

Asy, J. H. S, Herlina, Bayhakki. (2018). Hubungan Kualitas Tidur Terhadap Terjadinya Wasting Pada Anak Usia Sekolah.https://jom.unri.ac.id/index.ph $\mathrm{p} / \mathrm{JOMPSIK} /$ article/download/18806/1 $\underline{8178}$. Diakses pada tanggal 06 Juli 2019 pukul 01.05 wib.

Hanifratiwi. (2013). Hubungan Gangguan Tidur Terhadap Kualitas Hidup Anak Dengan Obesitas. Jurnal Media Medika Muda.

Iswidharmanjaya, D \& Beranda, A. (2014). Bila Si Kecil Bermain Gadget. Jakarta: Bisakimia.

Manumpil, M., Ismanto, Y., Onibala, F. (2015). Hubungan Penggunaan Gadget Dengan Tingkat Prestasi Siswa Di Sma Negeri 9 Manado. Ejoural Keperawatan (E-Kep) Volume 3. Nomor 2. April 2015.

Masyeni, C. (2010). Hubungan Kualitas Tidur dengan Konsentrasi Belajar Siswa SD Muhammadiyah Wirobrajan 3 Yogyakarta tahun 2010. Naskah Publikasi.digilib.unisayogya.ac.id/170 1/1/NASKAH\%20PUBLIKASI.pdf. Diakses pada tanggal 06 Juli 2019 pukul 02.00 wib. 
Jurnal Keperawatan Abdurrab

Vol 4. No.1, Juli 2020

Mawitjere, O. T., Onibala. F \& Ismanto, Y. A. (2017). Hubungan Lama Penggunaan Gadget Dengan Kejadian Insomnia Pada Siswa Siswi Di Sma Negeri 1 Kawangkoan. E-Journal Keperawatan (E-Kp) Volume 5 Nomor 1, Mei 2017.

Meirianto, M. T. (2018). Hubungan Antara Kecanduan Smarthphone dengan Kualitas Tidur pada Remaja. Naskah Publikasi.https://dspace.uii.ac.id/.../skri psi\%20Monika\%20Trisia\%20Meiriant o\%20\%2814320348. Diakses pada tanggal 20 Juli 2019 pukul 01.21 wib.

Mubarak, W. I., Indrawati, L., \& Susanto, J. (2015). Buku Ajar Ilmu Keperawatan Dasar Buku 2. Jakarta: Salemba Medika.

Nafiah, N. (2018). Hubungan Durasi Penggunaan Media Sosial Dengan Kualitas Tidur Pada Remaja Kelas Viii Di Smp Muhammadiyah 1 Yogyakarta. Naskah Publikasi. digilib.unisayogya.ac.id/4392/1/naspub \%20fix.pdf-min.pdf. Diakses pada tanggal 16 Juli 2019 pukul 16.05 wib.

Novitasari, W \& Khotimah, N. (2016). Dampak Penggunaan Gadget Terhadap Interaksi Sosial Anak Usia 5-6 Tahun. https://jurnalmahasiswa.unesa.ac.id/ind ex.php/paudteratai/article/view/17261.

Pandji, Aditya. (2014, 10 Juni). Orang Indonesia pakai smarthphone $3 \mathrm{jam}$ perhari.(https://lifestyle.kompas.com/r ead/2014/06/10/1625004/Orang.Indon esia.Pakai.Smartphone.3.Jam.Per.Hari. Diakses pada tanggal 02 Februari 2019 pukul 16.48 wib.

Permadi, A. (2017). Hubungan perilaku penggunaan gadget dengan kualitas
P-ISSN : 2541-2620

E-ISSN : 2579-8723

tidur pada anak usia remaja di sma negeri 1 srandakan bantul. https://docplayer.info/64991710-

Hubungan-perilaku-penggunaangadget-dengan-kuantitatif. Naskah Publikasi.

Poerwopoespito, EX. O. S. (2010). Mencegah dan Mengatasi Krisis Anak Melalui Perkembangan Sikap Mental Orang Tua. Jakarta: Dasar Segala Pelatihan.

Potter, P. A \& Perry, A. G. (2012). Buku Ajar Fundamental Keperawatan Konsep, Proses, dan Praktik Edisi 4 Volume 2. Jakarta: EGC.

Prasetyaningsih, Novia. (2017). Penggunaan Gadget pada Anak Usia Pendidikan Dasar di Jorong Laras Minang Nagari Kurnia Selatan Kecamatan Sungai Rumbai Kabupaten Dharmasyara Sumatera Barat. repo.stkip-pgrisumbar.ac.id/id/eprint/1134/.

Puspa, A. K., Loebis, R \& Nuswantoro, D. (2018). Pengaruh Penggunaan Gadget terhadap Penurunan Kualitas Penglihatan Siswa Sekolah Dasar. Ejournal.Unisba.Ac.Id/Index.Php/Gmh

Putri, H. (2015). Studi Deskriptif Gangguan Tidur pada Anak Usia 9-12 Tahun di SD Negeri Pisangan 1 Ciputat Tahun 2015.repository.uinjkt.ac.id/dspace/bit stream/.../38043/1/HILMIANA\%20PU TRI-FKIK.pdf. Naskah Publikasi.

Rozalia, M. F. (2017). Hubungan Intensitas Pemanfaatan Gadget Dengan Prestasi Belajar Siswa Kelas V Sekolah Dasar. Jurnal Pemikiran dan Pengembangan SD Volume 5, Nomor 2, September 2017: 2338-1140 (Halaman 722-731). 
Saifullah, M. (2017). Hubungan Penggunaan Gadget Terhadap Pola Tidur pada Anak Sekolah di UPT SD Negeri Gadingrejo II Pasuruan. repository.unair.ac.id/79251/2/FKP.N. 251-18\%20Sai\%20h.pdf. Diakses pada tanggal 18 Juli 2019 pukul 12.10 wib.

Syamsoedin, W. K. P. (2015). Hubungan Durasi Penggunaan Media Sosial dengan Kejadian Insomnia pada Remaja di SMA Negeri 9 Manado. Ejournal Keperawatan (E-Kp) Volume 3. Nomor 1. Februari 2015. 